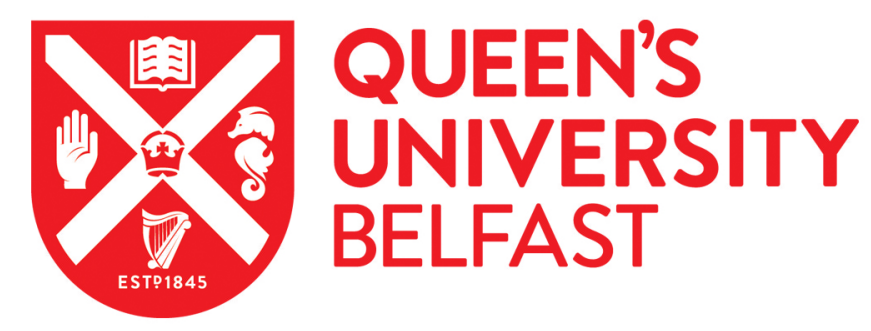

\title{
Antimicrobial peptide incorporated poly(2-hydroxyethyl methacrylate) hydrogels for the prevention of Staphylococcus epidermidis- associated biomaterial infections
}

Laverty, G., Gorman, S. P., \& Gilmore, B. F. (2012). Antimicrobial peptide incorporated poly(2-hydroxyethyl methacrylate) hydrogels for the prevention of Staphylococcus epidermidis-associated biomaterial infections. Journal of Biomedical Materials Research Part A, 100(7), 1803-1814. https://doi.org/10.1002/jbm.a.34132

Published in:

Journal of Biomedical Materials Research Part A

Document Version:

Peer reviewed version

Queen's University Belfast - Research Portal:

Link to publication record in Queen's University Belfast Research Portal

\footnotetext{
Publisher rights

Copyright ( $) 2012$ Wiley Periodicals, Inc.This work is made available online in accordance with the publisher's policies. Please refer to any applicable terms of use of the publisher
}

\section{General rights}

Copyright for the publications made accessible via the Queen's University Belfast Research Portal is retained by the author(s) and / or other copyright owners and it is a condition of accessing these publications that users recognise and abide by the legal requirements associated with these rights.

\section{Take down policy}

The Research Portal is Queen's institutional repository that provides access to Queen's research output. Every effort has been made to ensure that content in the Research Portal does not infringe any person's rights, or applicable UK laws. If you discover content in the Research Portal that you believe breaches copyright or violates any law, please contact openaccess@qub.ac.uk. 
Antimicrobial Peptide Incorporated poly(2-hydroxyethyl methacrylate)

Hydrogels for the Prevention of Staphylococcus epidermidis Associated Biomaterial Infections

Garry Laverty, Sean P. Gorman, Brendan F. Gilmore*

Biomaterials Research Group, School of Pharmacy, Queens University of Belfast,

Medical Biology Centre, 97 Lisburn Road, Belfast, BT9 7BL, UK

*Author for Correspondence

Dr Brendan F. Gilmore

Queen's University of Belfast,

Medical Biology Centre,

97 Lisburn Road,

Belfast BT9 7BL, UK

Tel: +44 (0) 2890972047

Fax: +44 (0) 2890247794

Email: b.gilmore@qub.ac.uk

Keywords: Peptides, antimicrobial, biofilm, hydrogel, biomaterials 


\begin{abstract}
The effectiveness of the antimicrobial peptide maximin-4, the ultrashort peptide $\mathrm{H}-$ Orn-Orn-Trp-Trp- $\mathrm{NH}_{2}$ and the lipopeptide $\mathrm{C}_{12}$-Orn-Orn-Trp-Trp- $\mathrm{NH}_{2}$ in preventing adherence of pathogens to a candidate biomaterial were tested utilising both matrix and immersion loaded poly(2-hydroxyethyl methacrylate) (poly(HEMA)) hydrogels. Anti-adherent properties correlated to both the concentration released and the relative antimicrobial concentrations of each compound against Staphylococcus epidermidis ATCC 35984, at each time point. Immersion loaded samples containing C12-OrnOrn-Trp-Trp- $\mathrm{NH}_{2}$ exhibited the lowest adherence profile for all peptides studied over 1,4 and 24 hours. The results outlined in the following paper show that antimicrobial peptides have the potential to serve as an important weapon against biomaterial associated infections.
\end{abstract}




\section{Introduction}

In the UK medical device related infections are estimated to cost somewhere in the range of $£ 7-11$ million per year. ${ }^{1}$ This can be attributed, in part, to both the increasing emergence of multidrug resistant pathogenic microorganisms and an increasing demand for implantable therapeutics or biomaterials to support normal physiological function in an ageing population. ${ }^{2}$ Implantable medical devices provide an optimum environment for the growth of microorganisms including opportunistic pathogens derived from the normal microflora of the body. ${ }^{3}$ In these scenarios bacteria exhibit a sessile biofilm phenotype, composed of aggregated microcolonies of cells surrounded by a protective extracellular polymeric matrix. ${ }^{4}$ The microbial colonisation of the surface and the formation of a hydrophobic, polysaccharide matrix provides microorganisms with a greater degree of protection against environmental stresses allowing biofilms to resist flow, increase utilisation of nutrients and energy, and increase antimicrobial resistance/tolerance. ${ }^{5}$

Whilst efforts have intensified to find novel alternatives to existing treatment strategies, successes have been limited and have failed to keep with the rapid emergence of resistance among pathogenic microorganisms. ${ }^{6}$ Therapeutic regimens tend only to act efficiently on multiplying bacteria by interference of cellular processes, leaving a reservoir of non-multiplying bacteria. ${ }^{7}$ As a result, their potential future use as chemotherapeutic agents is limited as eradication of the biofilm matrix and persister cells does not occur at the similarly low concentrations for planktonic kill. ${ }^{8}$ These non-multiplying dormant cells are often responsible for the failure of standard antimicrobial regimens and spread of resistant strains due to their low metabolism and reduced uptake of antibiotics that act on bacterial metabolic pathways. ${ }^{7}$ These persister cells are responsible for $60 \%$ of all clinical bacterial 
infection $^{9}$ and are linked to the reoccurrence of infections previously thought to be eradicated. ${ }^{10}$

One promising area of antimicrobial drug research is that of cationic antimicrobial peptides. Antimicrobial peptides in nature serve as important defensive weapons in the innate immune system of both prokaryotic and eukaryotic organisms against a broad spectrum of bacterial and fungal pathogens. ${ }^{11}$ Antimicrobial peptides exert their microbicidal effect via disruption of the microbial cell membrane together with intracellular action. ${ }^{12}$ The multiple modes of action utilised by antimicrobial peptides reduces the ability of microorganisms to develop resistance, with cidal activity also shown against bacteria resistant to standard antibiotics. ${ }^{13}$ Research conducted by Lai et al showed that the species of frog Bombina maxima produced a group of cationic antimicrobial peptides called maximins that demonstrated MIC values in the $\mu \mathrm{g} / \mathrm{mL}$ range against a broad spectrum of microbial pathogens including Staphylococcus aureus, Escherichia coli, Bacillus dysenteriae, Klebsiella pneumoniae and Candida albicans. ${ }^{14}$ Maximin-4 was the most potent peptide tested having the lowest minimum inhibitory concentration value of $2.7 \mu \mathrm{g} / \mathrm{mL}$ against Staphylococcus aureus. Maximin- 4 consists of twenty seven amino acids (GIGGVLLSAGKAALKGLAKVLAEKYAN) and has the potential to be synthesised via facile solid phase peptide synthesis. The initial target of these cationic antimicrobial peptides has been proven to be the negatively charged membrane of bacteria. $^{15}$

Structure activity relationship analyses have shown the activity and selectivity of cationic antimicrobial peptides to be governed by the overall hydrophobic:charge ratio of the primary amino acid sequence. ${ }^{16}$ Further work has allowed the identification of a structural pharmacophore (two units of bulk and two cationic 
charges) that acts as the minimum motif for antimicrobial activity. ${ }^{17}$ Based on this, Bisht and colleagues produced a series of amino terminal modified peptides containing two ornithine (Orn) (providing charge) and two tryptophan residues (Trp) (providing lipophilicity and bulk), with significantly reduced MIC values for amino terminal peptides in comparison to C-terminal carboxylic acids. ${ }^{18}$ The obvious advantage to the use of an ultrashort antimicrobial peptide is the large reduction in cost and ease of synthesis relative to synthetic variants of naturally occurring antimicrobial peptides. The attachment of an acyl chain to an active or inert ultrashort cationic peptide also potentially leads to an increased action against microorganisms in a similar way to native cationic antimicrobials. ${ }^{19}$

Previous work by in our laboratory showed the attachment of an N-terminal $\mathrm{C}_{12}$ (dodecyl) acyl substituent to the H-Orn-Orn-Trp-Trp- $\mathrm{NH}_{2}$ tetrapeptide standard produced an ultrashort lipopeptide with increased antimicrobial potency against established biofilm forms of Gram-positive staphylococci attributed to medical device related infections. ${ }^{20}$ A concentration as low as $15.63 \mu \mathrm{g} / \mathrm{mL}$ of $\mathrm{C}_{12}$-Orn-Orn-Trp-Trp$\mathrm{NH}_{2}$ was shown to completely eradicate mature 24 hour biofilms of Staphylococcus epidermidis ATCC 35984, with antibiofilm activity measured by determination of the minimum biofilm eradication concentrations (MBEC) utilising the Calgary biofilm device and MBEC Assay for Physiology \& Genetics. ${ }^{21}$

In this report we describe the synthesis, drug release characteristics of a range of novel antimicrobial peptide matrix and immersion loaded hydrogel polymers based on the monomer 2-hydroxyethyl methacrylate (HEMA), widely used in the manufacture of medical device coatings. Due to the promising antimicrobial properties displayed by the antimicrobial peptide maximin-4 and the lipopeptide $\mathrm{C}_{12}$ Orn-Orn-Trp-Trp- $\mathrm{NH}_{2}$ described by our group, we examine the use of these 
compounds incorporated in hydrogel matrices for the prevention of medical device infection, focusing on prevention of adherence by Staphylococcus epidermidis one of the main causative pathogens of device associated infections. Staphylococcus epidermidis was selected as this microorganism is representative of all Gram-positive pathogens in that it is responsible for a large proportion of medical device related infections due, in part, to its ability to form a biofilm resistant to standard antimicrobial regimens. ${ }^{22}$ Vancomycin was selected as a comparative control for standard antimicrobials due to its use clinically, particularly with regard to staphylococcal infections. ${ }^{23}$

\section{Experimental}

\subsection{Materials}

Rink amide 4-(2',4'-dimethoxyphenyl-Fmoc-aminomethyl)-phenoxyacetamidoMHBA (MBHA) resin, all 9-fluorenylmethoxy carbonyl (Fmoc) L-amino acids (Fmoc-Orn(Boc)-OH and Fmoc-Trp(Boc)-OH) and 2-(1H-benzotriazole-1-yl)1,1,3,3-tetramethyluronium hexafluorophosphate (HBTU), N-Methyl-2-pyrrolidone (NMP), piperidine, trifluoroacetic acid, triisopropylsilane and thioanisole were obtained from Merck Chemicals Ltd. (Nottingham, UK). Fatty acid; dodecanoic (lauric) acid, phosphate buffer saline (PBS) tablets and vancomycin (as hydrochloride hydrate) were obtained from Sigma-Aldrich (Dorset, UK). All other reagents/solvents were peptide synthesis grade. HEMA, 1\% ethylene glycol dimethacrylate (EGDMA) and $0.4 \%$ benzoyl peroxide were obtained from SigmaAldrich (Dorset, UK). 


\subsection{Peptide Synthesis}

All Peptides were synthesised using standard Fmoc solid phase protocols on Rink Amide MHBA resin, using a CEM Liberty (Buckingham, UK) microwave enhanced automated peptide synthesiser at 1 millimolar scale as previously reported. ${ }^{20}$ Removal of the Fmoc grouping from the protected resin and amino acids (deprotection) occurred in 20\% piperidine in Dimethylformamide. Peptide elongation/coupling was performed using HBTU/NMP and a three-fold molar excess of each Fmoc-protected amino acid or free hydrocarbon containing acid derivative. Coupling occurred at standard (microwave enhanced) amino acid coupling conditions (18 Watt, $75^{\circ} \mathrm{C}, 300$ seconds) and was employed for all syntheses. Automated synthesis yielded synthesised peptide attached to the Rink amide MHBA resin. All synthesised peptides were cleaved from the resin in a round bottom flask using $95 \%$ Trifluoroacetic acid, $2.5 \%$ triisopropylsilane and $2.5 \%$ thioanisole ( 2 hours, room temperature and pressure). The synthesised peptide, present in the solvent phase, was separated from the resin by vacuum filtration under reduced pressure using a Büchner funnel and flask. Excess solvent was removed under reduced pressure via rotary evaporation. The peptide remaining was precipitated using cold diethyl ether, lyophilised and stored at $-20^{\circ} \mathrm{C}$ until required for further analysis. Peptide purity was analysed by Reverse Phase-High Performance Liquid Chromatography (RP-HPLC) using a Gemini C18, $250 \mathrm{~mm}$ x $4.6 \mathrm{~mm}$ column (Phenomonex, UK), a 2-60\% acetonitrile gradient [30min] in $0.05 \%$ trifluoroacetic acid-water at a flow rate of 1 $\mathrm{mL} / \mathrm{min}$. All peptides/lipopeptides were found to have $>90 \%$ purity. 


\subsection{Strains \& Growth Conditions}

Staphylococcus epidermidis ATCC 35984 was stored at $-80{ }^{\circ} \mathrm{C}$ in Microbank vials (Pro-Lab Diagnostics, Cheshire, UK) and subcultured in Müller Hinton Broth (MHB) before testing.

\subsection{Matrix Loaded Poly(HEMA) Hydrogel Synthesis}

Matrix loaded poly(HEMA) polymers were synthesised by free radical solution polymerization of the monomer, HEMA with chemical initiation in a similar method to that employed by Parsons et al. ${ }^{24} 1 \%$ EGDMA was used as a crosslinker with $0.4 \%$ benzoyl peroxide used as a radical initiator. H-Orn-Orn-Trp-Trp- $\mathrm{NH}_{2}, \mathrm{C}_{12}$-OrnOrn-Trp-Trp-NH $\mathrm{N}_{2}$, maximin-4 and vancomycin were added after free radical initiation at $0.5 \%, 1 \%$ and $5 \%$ ratios relative to total hydrogel content. Dissolution was achieved by stirring at 1000rpm for 2 hours at room temperature (to ensure homogeneity, with visual conformation) and the mixture was injected into a mould comprising of two vertical glass plates lined with release liner (3M), separated by silicon tubing of diameter $3 \mathrm{~mm}$ and cured in a Gallenkamp box oven at $90^{\circ} \mathrm{C}$ for 2 hours. A non-drug containing poly(HEMA) hydrogel was produced to provide positive controls. Each antimicrobial was proven to be thermally stable under the conditions employed for hydrogel synthesis $\left(90^{\circ} \mathrm{C}\right.$ for 2 hours). Antimicrobial activity was linked to structural stability in a similar manner to the theory employed by Lappe et al. ${ }^{25}$ Values for minimum inhibitory (MICs) and minimum bactericidal concentrations (MBCs) against Staphylococcus epidermidis ATCC 35984, utilising National Committee for Clinical Laboratory Standards (NCCLS) guidelines in a method similar to that described by Andrews, ${ }^{26}$ were shown to be the same both before and after heat treatment. 


\subsection{Immersion Loaded Poly(HEMA) Hydrogel Synthesis}

Immersion loaded hydrogels were produced by swelling of non drug containing poly(HEMA) hydrogels in drug containing solutions. ${ }^{27}$ Non-drug containing poly(HEMA) hydrogels were synthesised as previously for the poly(HEMA) control for matrix loaded hydrogels. After curing hydrogels were washed in distilled water (replaced with fresh solution each day) at room temperature for 14 days to ensure removal of reaction products/unreacted monomers. ${ }^{24}$ Washed hydrogels were stored in distilled water until ready to be cut for analysis using a sterile size number 8 cork borer $(1 \mathrm{~cm}$ diameter). Drug containing immersion solutions $(20 \mathrm{mg} / \mathrm{mL}, 10 \mathrm{mg} / \mathrm{mL}$ and $5 \mathrm{mg} / \mathrm{mL}$ ) were formed by addition of H-Orn-Orn-Trp-Trp- $\mathrm{NH}_{2}, \mathrm{C}_{12}$-Orn-OrnTrp-Trp- $\mathrm{NH}_{2}$, maximin-4 and vancomycin to $10 \mathrm{mLs}$ sterile PBS of $\mathrm{pH} 7.4$ (pH was tested using a calibrated Hanna pH 209 pH meter) in sterile McCartney jars. Circular samples of poly(HEMA) hydrogels ( $1 \mathrm{~cm}$ diameter, $3 \mathrm{~mm}$ length) were dried in a Gallenkamp box oven $\left(60^{\circ} \mathrm{C}\right.$ for 24 hours $)$ to ensure that residual moisture was removed and a constant weight achieved (weighed at 0,23 and 24 hour time points). These dried poly(HEMA) samples were immersed in drug solution for 24 hours at room temperature before release and adherence analysis.

\subsection{Release Properties of Antimicrobials via Matrix and Immersion Loaded}

\section{Poly(HEMA) Hydrogels}

Samples of $0.5 \%, 1 \%, 5 \%$ matrix loaded and $20 \mathrm{mg} / \mathrm{mL}, 10 \mathrm{mg} / \mathrm{mL}, 5 \mathrm{mg} / \mathrm{mL}$ immersion loaded hydrogels of H-Orn-Orn-Trp-Trp- $\mathrm{NH}_{2}, \mathrm{C}_{12}$-Orn-Orn-Trp-Trp-NH 2 , maximin-4 and vancomycin were manufactured as described in Section 2.4 and 2.5. Each sample was placed in a preheated $10.5 \mathrm{~mL}$ vial containing $10 \mathrm{mLs}$ of PBS $(\mathrm{pH}$ 7.4) at $37^{\circ} \mathrm{C}$. Sample vials were then transferred to a Grant SS40-D shaking bath for a 
total of 2 weeks at $37^{\circ} \mathrm{C}$ and 100 strokes per minute. Five replicates were studied at each drug concentration. Each hydrogel sample was removed at 0, 0.25, 0.5, 0.75, 1, $1.5,2,4,6,18,24,78,168,192,216,264$, and 336 hours and placed in fresh preheated $10.5 \mathrm{~mL}$ vial containing $10 \mathrm{mLs}$ of $\mathrm{PBS}(\mathrm{pH} 7.4)$ at $37^{\circ} \mathrm{C}$. PBS solution with released drug was then analysed for concentration of drug via UV-visible spectroscopy at a defined peak wavelength $(\mathrm{nm})$ and a fresh calibration curve utilising a Varian Cary 50 UV-visible spectrophotometer, a quartz cuvette and following the Beer-Lambert law. All release studies were carried out under sink conditions, that is, in a volume of dissolution medium that is at least 5 to 10 times the saturation volume. ${ }^{28}$ Modelling of drug release profiles was performed using a simple Power Law based equation derived by Ritger and Peppas. ${ }^{29}$ Modelling of release data in this way can allow for the calculation of the total quantity of drug eluted over a particular time period. In order to obtain the most accurate data from experimental results, Power Law modelling is typically applied to the first $60 \%$ of total drug release curves. ${ }^{30}$

$$
\frac{M_{t}}{M \infty}=K t^{n}
$$

Where $M_{t}$ and $M \infty$ are the absolute cumulative amount of drug released at time $\mathrm{t}$ and infinite time respectively. $K$ is a constant that incorporates both the structural and geometric character of the device, whilst the release exponent $n$ indicates the mechanism of drug release.

The Power law was used to model the drug release mechanism via determination of the release exponent $(n)$. When the $\log _{10}$ fraction of total drug released is plotted against the $\log _{10}$ time, for values up to $60 \%$ of total drug released, the release exponent $(n)$ is equivalent to the gradient of this graph. ${ }^{31}$ The above 
equation, representing a linear fit model, can be modified to a logarithmic function according to Wang et al. ${ }^{32}$

$$
\log (\% \text { released })=\log \left(\frac{M_{t}}{M \infty}\right)=\log K+n \log t
$$

To characterise different release mechanisms Peppas et al used this $n$ value, with the values obtained with samples in the shape of flat disks (radius>thickness). ${ }^{30}$ This model is used to analyse the release of polymeric dosage forms, when the release mechanism is undefined or more than one type of release phenomena could be involved..$^{33}$

\subsection{Anti-adherent Properties of Matrix and Immersion Loaded Poly(HEMA)}

\section{Hydrogels against Staphylococcus epidermidis ATCC 35984}

The anti-adherent properties of synthesised poly(HEMA) hydrogels were evaluated by modification of a method used by Jones and colleagues. ${ }^{34,35}$ Inocula of the biofilm forming pathogen Staphylococcus epidermidis ATCC 35984 were incubated overnight in the orbital incubator for approximately $18-24$ hours so that the organism was in the late stationary growth phase. Cultures were centrifuged in sterile centrifuge tubes at $3000 \mathrm{rpm}$ for $15 \mathrm{~min}$ using a Sigma 3-16P centrifuge. The supernatant liquid was poured into disinfectant and the pellet resuspended in PBS (pH 7.4) to obtain an optical density of $0.9(540 \mathrm{~nm})$ using a WPA colourwave CO7500 colourimeter. This gave give an approximate inoculum size of $4.5 \times 10^{8}$ colony forming units per $\mathrm{mL}(\mathrm{CFU} / \mathrm{mL})$ as verified by a Miles and Misra viable count. The hydrogels, manufactured disks cut with a size number 8 cork borer $(1 \mathrm{~cm}$ diameter $)$ as per release method, were placed on sterile hypodermic syringe needles, five samples per needle. Positive controls provided for matrix and immersion loaded drugs by non drug containing poly(HEMA) hydrogels. $20 \mathrm{mLs}$ of the inoculum was added to a 
sterile McCartney bottle containing each poly(HEMA) samples (one McCartney corresponding to each time point and sample concentration). This volume was sufficient to completely cover the materials. These were placed in an incubator shaker and removed at 1, 4 and 24 hour time intervals. Using sterile forceps each needle holding the five disks was removed and placed in a fresh sterile McCartney containing approximately $20 \mathrm{mLs}$ of quarter strength ringers solution (QSRS). Shaken vigorously for 30 seconds, to ensure non-adhered organisms/materials were removed, this procedure was repeated twice more. To remove adhered organisms each hydrogel disc was placed in a separate sterile test tube containing 10mLs QSRS and sonicated for 10 minutes using a Branson 3510 sonic bath and vortexed for 30 seconds at $42 \mathrm{KHz}( \pm 6 \%)$. It has been shown previously that sonication, at this level, does not affect either microbial viability or morphology. ${ }^{36}$ The QSRS containing resuspended bacteria was decanted into another sterile test tube so as to prevent readherence. A Miles and Misra viable count was performed to determine the number of organisms adhered via serial dilutions with culturing on Müeller-Hinton agar plates. These were incubated overnight and then counted (CFU/disc) before calculation of the percentage adhered of the number of colony forming units per disc via comparison to the positive control.

\subsection{Statistical Analysis}

Adherence characteristics of H-Orn-Orn-Trp-Trp- $\mathrm{NH}_{2}, \mathrm{C}_{12}$-Orn-Orn-Trp-Trp- $\mathrm{NH}_{2}$, maximin-4 and vancomycin matrix loaded and immersion loaded, 1\% EGDMA crosslinked, poly(HEMA) hydrogels were all compared using a one way ANOVA, with a Tukey-Kramer multiple comparisons test used to identify individual differences. In all cases a probability of $\mathrm{p} \leq 0.05$ denoted significance. 


\section{Results and discussion}

\subsection{Release Properties of Antimicrobials via Matrix and Immersion Loaded}

Poly(HEMA) Hydrogels

EGDMA (1\%) crosslinked poly(HEMA) hydrogels were utilised as a potential medical device coating and antimicrobial carrier due to its ability to release entrapped drug in aqueous solution and their excellent biocompatibility. ${ }^{37}$ The release of drug and swelling characteristics can be altered via changing of the crosslinking density. ${ }^{38}$ In this study the crosslinking density was kept constant at 1\% using EGDMA in order to determine the effect of antimicrobial peptide concentration on release and adherence kinetics. ${ }^{24}$ Poly(HEMA) hydrogels consist of separate regions containing water and polymer chains, with the water containing regions providing pores for the release of drug molecules. ${ }^{39}$ The monomer of HEMA possesses anionic character which is also present in its polymeric form. The use of anionically charged hydrogels allow strong electrostatic interactions to develop with cationic molecules such as $\mathrm{H}$ Orn-Orn-Trp-Trp- $\mathrm{NH}_{2}, \mathrm{C}_{12}$-Orn-Orn-Trp-Trp- $\mathrm{NH}_{2}$ and maximin-4 for both matrix and immersion loaded hydrogels, as similarly shown for cationic compounds such as benzalkonium and cetrimide in Poly(HEMA) based contact lens. ${ }^{40,41}$ This property enables the retention of these cationic compounds with the possibility of favourable sustained release kinetics over many days/weeks.

Figure 1 is provided as an example of the cumulative percentage drug release of the antimicrobial peptides, specifically $\mathrm{C}_{12}$-Orn-Orn-Trp-Trp- $\mathrm{NH}_{2}$, from a $0.5 \%$, $1 \%$ and $5 \%$ matrix loaded poly(HEMA) hydrogel over a period of 2 weeks. Both HOrn-Orn-Trp-Trp- $\mathrm{NH}_{2}$ and maximin-4 show similar release patterns to matrix and immersion loaded $\mathrm{C}_{12}$-Orn-Orn-Trp-Trp- $\mathrm{NH}_{2}$ hydrogels. 5\% matrix loaded poly(HEMA) showed a release of $2420 \mu \mathrm{g}$ of peptide over 2 weeks ( $36.9 \%$ compared 
to theoretical). $1 \%(60.0 \%$ of theoretical released in 2 weeks $)$ and $0.5 \%(94.6 \%$ of theoretical released in 2 weeks) $\mathrm{C}_{12}$-Orn-Orn-Trp-Trp-NH 2 matrix loaded poly(HEMA) show a similar pattern of increasing percentage drug release relative to theoretical concentration when the percentage drug within the hydrogel decreases. The lipophilicity:charge balance of $\mathrm{C}_{12}$-Orn-Orn-Trp-Trp- $\mathrm{NH}_{2}$ may have allowed it to be retained within the polymer matrix at higher concentrations $(5 \%)$ but still be sufficiently soluble to release a larger percentage of matrix loaded compound over 2 weeks.

Immersion loaded hydrogels, shown by the example of 20,10 and $5 \mathrm{mg} / \mathrm{mL}$ immersion loaded $\mathrm{C}_{12}$-Orn-Orn-Trp-Trp- $\mathrm{NH}_{2}$ poly(HEMA) hydrogels in Figure 2, did not retain any drug after the 2 week release assay, all compounds were released within 78 hours. These results are indicative of reduced interactions of the drug solutions with the poly(HEMA) matrix compared with matrix loaded hydrogels. For example, the theoretical mass of $\mathrm{C}_{12}$-Orn-Orn-Trp-Trp- $\mathrm{NH}_{2}$ present in a poly(HEMA) hydrogel sample after 24 hour immersion in a $10 \mathrm{~mL}$ solution of $20 \mu \mathrm{g} / \mathrm{mL}$ (maximum concentration evaluated) was $12000 \mu \mathrm{g}$. After 78 hours, $10900 \mu \mathrm{g}$ of $\mathrm{C}_{12}$-Orn-Orn$\operatorname{Trp}-\operatorname{Trp}-\mathrm{NH}_{2}(90.8 \%)$ was released.

Analysis of the cumulative percentage of experimental drug released from poly(HEMA) hydrogels over 2 weeks showed for matrix loaded hydrogels that up to $70 \%$ of the cumulative drug released over 2 weeks was released in the first 24 hours irrespective of percentage drug loading. In vitro results for immersion loaded poly(HEMA) hydrogels show $100 \%$ of all compounds were released within 78 hour contact with PBS, with almost $70 \%$ of the cumulative drug released over 2 weeks released in 4 hours. 
The ideal scenario, as provided in the first 3 days by both matrix and immersion loaded poly(HEMA) hydrogels, is that the release of the antimicrobial compound should be high initially (also known as burst release) when the risk of infection and microbial adherence is at its greatest, followed by a longer period of controlled drug release at microbicidal levels. ${ }^{42}$ A longer period of controlled antimicrobial release is absent in immersion loaded hydrogels and they are therefore at increased risk to the development of infection after 78 hours. Release of polymer could initially be reduced and delayed by increasing the degree of crosslinking. ${ }^{43}$

Determination of the release exponent $(n)$ allowed information to be obtained about the physical mechanism of drug release from both matrix and immersion loaded poly(HEMA), $1 \%$ crosslinked hydrogels. The diffusional exponent, $n$, is dependent on the geometry of the device as well as the physical mechanism for release and is thus varied between slab and cylindrical polymers. ${ }^{44}$ All matrix and immersion loaded samples had a value of $n$ greater than 0.5 but less than 1 corresponding to anomalous transport which occurred as a result of a coupling of both Fickian diffusion and polymer relaxation. Also termed non-Fickian release this type of drug release occurs due to a combination of macromolecular relaxations and Fickian diffusion. ${ }^{45}$ An exponent value of 1 represents time independent zero order release, whereas a value equal to 0.5 represents purely diffusion controlled release. ${ }^{46}$ More commonly, as in this case, both erosion and diffusion contribute to the eventual release of drug from the delivery vehicle via anomalous transport. ${ }^{47}$

The mechanism of drug release is highly dependent on the solubility of the drug and the swelling and erosion properties of the polymer matrix. Highly soluble drugs, for example vancomycin, will diffuse easily through the hydrogel layer with drugs with poor aqueous solubility released via a slower erosion and anomalous 
diffusion mechanism resulting from the relaxation of polymer chains. ${ }^{48}$ The importance of solubility is demonstrated by comparison of the exponent values obtained for immersion loaded drugs. Vancomycin possessed the lowest value of $n$ all compounds tested $(20 \mu \mathrm{g} / \mathrm{mL}$ loading, $n=0.7251 \pm 0.01)$. This figure is the closest to the true diffusion value of $n=0.5$ of all the immersion loaded drugs tested due to the high solubility of vancomycin in comparison to the peptides tested. The aqueous solubility of vancomycin $(152 \mathrm{mg} / \mathrm{mL})$ in PBS is almost three times greater than $\mathrm{H}$ Orn-Orn-Trp-Trp- $\mathrm{NH}_{2}(65 \mathrm{mg} / \mathrm{mL})$, the most soluble peptide tested. The majority of release exponent values for immersion loaded drugs, as displayed in Table 4, were closer to 1, indicating that release is more dependent on erosion and/or relaxation of the polymeric chains. It is possible that immersion in concentrated solutions (as low as $5 \mathrm{mg} / \mathrm{mL}$ ) of cationic antimicrobial peptides may have compromised the polymer structure. These peptides have demonstrated detergent like properties against both prokaryotic and eukaryotic membranes. ${ }^{20}$ The use of similar cationic disinfectants such as benzalkonium chloride has been shown to have a deleterious effect on poly(HEMA) contact lenses. ${ }^{40}$ It is possible that similar erosion by cationic peptides may influence release to a higher degree than diffusion. For matrix loaded hydrogels, as outlined in Table 3, the highest value for $n$ was $0.6230 \pm 0.03$ for poly(HEMA) containing $0.5 \% \mathrm{C}_{12}$-Orn-Orn-Trp-Trp- $\mathrm{NH}_{2}$. Thus, although release is defined as anomalous transport, release exponent values are closer to that of diffusional release $(n=1)$. 


\subsection{Anti-adherent Properties of Matrix and Immersion Loaded Poly(HEMA)}

Hydrogels against Staphylococcus epidermidis ATCC 35984

The anti-adherent properties of matrix and immersion loaded H-Orn-Orn-Trp-Trp$\mathrm{NH}_{2}, \mathrm{C}_{12}$-Orn-Orn-Trp-Trp- $\mathrm{NH}_{2}$, maximin-4 and vancomycin containing poly(HEMA) hydrogels were tested against the Gram-positive bacterium Staphylococcus epidermidis ATCC 35984. This strongly adherent, slime-producing, pathogenic strain of Staphylococcus epidermidis utilises the icaADBC operon to produce polysaccharide intercellular adhesin ${ }^{49}$ and has commonly been used to evaluate the anti-biofilm activity of medical device and compounds in the literature. ${ }^{21,50,51}$ Results are displayed in Figures 3-8 as mean percentage adherence in proportion to positive poly(HEMA) controls as utilised in many studies. ${ }^{24}$ Analysis of results show a correlation between both the amount of compound released; the relative MICs, MBCs and MBECs of each compound against Staphylococcus epidermidis ATCC 35984 as reported previously by our group $;{ }^{20}$ the mean percentage adherence and the time point analysed. All matrix and immersion loaded vancomycin, maximin-4, HOrn-Orn-Trp-Trp- $\mathrm{NH}_{2}$ and $\mathrm{C}_{12}$-Orn-Orn-Trp-Trp- $\mathrm{NH}_{2}$ display highly significant reduction in adherence $(\mathrm{p}<0.001)$ compared to positive controls at the same time points.

For matrix loaded poly(HEMA) hydrogels, all 5\% peptide containing samples showed reduced adherence at 1, 4 and 24 hours when compared with $1 \%$ and $0.5 \%$ due to an increased concentration of antimicrobial peptide released at each time point. At 1 hour both 5\% matrix loaded $\mathrm{C}_{12}$-Orn-Orn-Trp-Trp- $\mathrm{NH}_{2}$ and maximin-4 had a mean percentage adherence of $0 \%$ relative to the positive control. This corresponds to a mean release of $544 \mu \mathrm{g}$ and $549 \mu \mathrm{g}$ for $\mathrm{C}_{12}$-Orn-Orn-Trp-Trp- $\mathrm{NH}_{2}$ and maximin-4 respectively (Table 1). As this release occurred in 10mLs of PBS, the concentration 
of $\mathrm{C}_{12}$-Orn-Orn-Trp-Trp- $\mathrm{NH}_{2}$ was $54.4 \mu \mathrm{g} / \mathrm{mL}$ and $54.9 \mu \mathrm{g} / \mathrm{mL}$ for maximin-4 after 1 hour. This represents a concentration of more than 3.48 times the MBEC for $\mathrm{C}_{12}$ Orn-Orn-Trp-Trp-NH $2(15.63 \mu \mathrm{g} / \mathrm{mL})^{20}$ and 1.75 times that for maximin-4 (MBEC: $31.25 \mu \mathrm{g} / \mathrm{mL}$, previously unreported). Therefore non-adherence of microorganism to poly(HEMA) samples may be due to rapid eradication of both planktonic and biofilm forms of microorganisms by both $\mathrm{C}_{12}$-Orn-Orn-Trp-Trp- $\mathrm{NH}_{2}$ and maximin-4, in the area surrounding the hydrogel, at the microbicidal concentrations demonstrated. Results at 4 and 24 hours correspond to reduced adhesion relative to positive control due to increased concentration and microbicidal action of the matrix loaded peptide antimicrobials. At 24 hours 0.5, 1\% and 5\% $\mathrm{C}_{12}$-Orn-Orn-Trp-Trp- $\mathrm{NH}_{2}$ demonstrated $0 \%$ mean percentage adherence corresponding to a cumulative release of 454 $(45.4 \mu \mathrm{g} / \mathrm{mL}), 554(55.4 \mu \mathrm{g} / \mathrm{mL})$ and $1650 \mu \mathrm{g}(165 \mu \mathrm{g} / \mathrm{mL})$ with concentrations again above MBEC for $\mathrm{C}_{12}$-Orn-Orn-Trp-Trp- $\mathrm{NH}_{2}$ against Staphylococcus epidermidis ATCC 35984. $1 \%$ (concentration of peptide present: $37.8 \mu \mathrm{g} / \mathrm{mL}$ ) and $5 \%$ (concentration of peptide present: $192 \mu \mathrm{g} / \mathrm{mL}$ ) maximin-4 (MBEC: $31.25 \mu \mathrm{g} / \mathrm{mL}$ ) also demonstrated $0 \%$ adherence for similar reasons. Although the matrix loaded tetrapeptide $\mathrm{H}-\mathrm{Orn}-\mathrm{Orn}-\mathrm{Trp}-\mathrm{Trp}-\mathrm{NH}_{2}$ displayed reduced adherence relative to positive poly(HEMA) control, $0 \%$ adherence and total non-adherence of Staphylococcus epidermidis ATCC 35984 was not achieved. At time 24 hours and a matrix loaded concentration of 5\%, H-Orn-Orn-Trp-Trp- $\mathrm{NH}_{2}$ only reduced adherence to its lowest value of $36.5 \% \pm 5.10 \%$. This is due most likely to the sub-MBEC value $(95.9 \mu \mathrm{g} / \mathrm{mL}$, MBEC: $500 \mu \mathrm{g} / \mathrm{mL})$ of H-Orn-Orn-Trp-Trp-NH 2 released from a $5 \%$ poly(HEMA) hydrogel after 24 hours.

Matrix loaded maximin-4 and $\mathrm{C}_{12}$-Orn-Orn-Trp-Trp- $\mathrm{NH}_{2}$ hydrogels were shown to have statistically significant reduction $(\mathrm{p}<0.001)$ in adherence compared to 
the same concentrations of vancomycin after 1 hour. This can be attributed to rapid membrane targeting by these antimicrobial peptides. Vancomycin's mechanism of action is mainly focused on disruption of cell wall synthesis and possibly also through inhibition of bacterial RNA synthesis. ${ }^{52}$ This targeting of metabolic pathways leads to a reduction in initial kill of Staphylococcus epidermidis ATCC 35984 and an increase in adherence relative to both maximin- 4 and $\mathrm{C}_{12}$-Orn-Orn-Trp-Trp- $\mathrm{NH}_{2}$. Similar results are obtained for immersion loaded hydrogels of vancomycin. Despite a cumulative mass of $2900 \mu \mathrm{g}$ released from $20 \mathrm{mg} / \mathrm{mL}$ immersion loaded vancomycin after 1 hour, adherence is still significantly higher $(\mathrm{p}<0.001)$ than that of the three antimicrobial peptides. No significant difference $(\mathrm{p}>0.05)$ between matrix and immersion loaded vancomycin, maximin-4 and $\mathrm{C}_{12}$-Orn-Orn-Trp-Trp- $\mathrm{NH}_{2}$ adherence are observed at similar concentrations after 4 hours. After 4 hours vancomycin demonstrates effective cidal action via its targeting of metabolic pathways. Similar results are obtained for immersion loaded hydrogels of vancomycin.

Immersion loaded H-Orn-Orn-Trp-Trp- $\mathrm{NH}_{2}, \mathrm{C}_{12}$-Orn-Orn-Trp-Trp- $\mathrm{NH}_{2}$, maximin-4 and vancomycin show a similar trend of adherence related to concentration of compound released. All concentrations of $\mathrm{C}_{12}$-Orn-Orn-Trp-Trp$\mathrm{NH}_{2}$ and maximin- 4 demonstrate $0 \%$ adherence after 1 and 4 hours exposure to Staphylococcus epidermidis ATCC 35984. These results occur due to the relatively rapid release of high concentrations of antimicrobial peptide within 4 hours. For example, $5 \mathrm{mg} / \mathrm{mL}$ immersion loaded poly(HEMA) released a cumulative $725 \mu \mathrm{g}$ (concentration: $72.5 \mu \mathrm{g} / \mathrm{mL}$ ) of $\mathrm{C}_{12}$-Orn-Orn-Trp-Trp- $\mathrm{NH}_{2}$ after 1 hour, 4.64 times that of the MBEC $(15.63 \mu \mathrm{g} / \mathrm{mL})$ against Staphylococcus epidermidis ATCC 35984. Vancomycin shows a maximum reduction in adherence to $0 \pm 0 \%$ for $20 \mathrm{mg} / \mathrm{mL}$ immersion loaded and $3.55 \% \pm 1.27 \%$ for $5 \%$ matrix loaded poly(HEMA) samples 
after 24 hours. Complete bactericidal non-adherence was not achieved within 4 hours, similar to results obtained by Kodjikian et al, ${ }^{53}$ due to the bactericidal mechanism of action of vancomycin focusing on time dependant metabolic/synthesis pathways. Results published by Ceri et al, ${ }^{21}$ show vancomycin to have an MBEC value above tested concentration limits $(>1000 \mu \mathrm{g} / \mathrm{mL})$ therefore there is an increasing need for alternative antimicrobials to combat the threat posed by biofilm related resistance. Initial comparison of adherence results for both matrix and immersion loaded hydrogels show immersion loaded samples to have a more favourable lower adherence profile for all peptides over 1, 4 and 24 hours. A slower sustained release of peptide from matrix loaded samples resulted in longer times to reach MBEC and microbicidal concentrations, resulting in increased adherence of Staphylococcus epidermidis ATCC 35984.

\section{Conclusions}

In summary, the use of antimicrobial peptides and in particular $\mathrm{C}_{12}$-Orn-Orn$\operatorname{Trp}-\operatorname{Trp}-\mathrm{NH}_{2}$ described here as antimicrobial agents for the prevention of device associated infections by Staphylococcus epidermidis show significant promise. Staphylococcus epidermidis is a major causative organism in the infection of peritoneal dialysis and intravascular catheters; prosthetic valve endocarditis; prosthetic implants and contact lenses. ${ }^{54}$ The significance of these results are that improved clinical outcomes may be provided by the potential use of antimicrobial peptides either alone or in combination with standard therapeutic regimens. The rapid cidal action of $\mathrm{C}_{12}$-Orn-Orn-Trp-Trp- $\mathrm{NH}_{2}$ and maximin-4 via their action on bacterial membranes demonstrates that these compounds could have potential in the prevention and treatment of medical device related infections. This approach may 
lead to the utilisation of potent antimicrobial peptides which, due to poor pharmacological profile and bioavailability issues, have been (up until now) regarded as of little clinical value. The direct incorporation of antimicrobial peptides into hydrogel matrices requires still more refinement to match release profile with device residence time in the body, however, delivery in this format facilitates a localised antimicrobial effect whilst avoiding the potential side effects of such agents in vivo. The demand for novel antimicrobials, which are active against these biofilm forming resistant pathogens, has become one of the greatest challenges in the management of infectious diseases such as medical device related infection. Efforts have intensified to discover novel alternatives but at a decreasing rate compared with the emergence of resistant strains. Cationic antimicrobials with their multiple membranous, metabolic and cellular microbial targets reduce the ability of these pathogens to develop resistance. With thousands of naturally sourced antimicrobial peptides and millions of potential synthetic possibilities antimicrobial have the potential to solve the impending antimicrobial crisis. ${ }^{55}$

\section{References}

1. Darouiche RO. Treatment of infections associated with surgical implants. N Engl J Med. 2004;350:1422-9.

\section{Baddour LM, Infectious Diseases Society of America's Emerging Infections}

Network. Long-term suppressive antimicrobial therapy for intravascular devicerelated infections. Am J Med Sci. 2001;322:209-12.

3. Caramia G, Atzei A, Fanos V. Probiotics and the skin. Clin Dermatol. 2008;26:411. 
4. Donlan RM. Biofilms: microbial life on surfaces. Emerg Infect Dis. 2002;8:88190.

5. Mah TF, O'Toole GA. Mechanisms of biofilm resistance to antimicrobial agents. Trends Microbiol. 2001;9:34-9.

6. Falagas ME, Fragoulis KN, Karydis I. A comparative study on the cost of new antibiotics and drugs of other therapeutic categories. PLoS ONE. 2006;1:e11.

7. Coates $\mathrm{AR}, \mathrm{Hu} \mathrm{Y}$. New strategies for antibacterial drug design: targeting nonmultiplying latent bacteria. Drugs R D. 2006;7:133-51.

8. Olson ME, Ceri H, Morck DW, Buret AG, Read RR. Biofilm bacteria: formation and comparative susceptibility to antibiotics. Can J Vet Res. 2002;66:86-92.

9. Costerton JW, Stewart PS, Greenberg. EP Bacterial biofilms: a common cause of persistent infections. Science. 1999;284:1318-22.

10. Keren I, Kaldalu N, Spoering A, Wang Y, Lewis K. Persister cells and tolerance to antimicrobials. FEMS Microbiol Lett. 2004;230:13-8.

11. Brown KL, Hancock RE. Cationic host defense (antimicrobial) peptides. Curr Opin Immunol. 2006;18:24-30.

12. Brogden KA. Antimicrobial peptides: pore formers or metabolic inhibitors in bacteria?. Nat Rev Microbiol. 2005;3:238-50.

13. Giuliani A, Pirri G, Nicoletto SF. Antimicrobial peptides: an overview of a promising class of therapeutics. Eur J Biol. 2007;2:1-33.

14. Lai R, Zheng YT, Shen JH, Liu GJ, Liu H, Lee WH, Tang SZ, Zhang Y. Antimicrobial peptides from skin secretions of Chinese red belly toad Bombina maxima. Peptides. 2002;23:427-35.

15. Powers JP, Hancock RE. The relationship between peptide structure and antibacterial activity. Peptides. 2003;24:1681-91. 
16. Hwang PM, Vogel HJ. Structure-function relationships of antimicrobial peptides. Biochem Cell Biol. 1998;76:235-46.

17. Strom MB, Haug BE, Skar ML, Stensen W, Stiberg T, Svendsen JS. The pharmacophore of short cationic antibacterial peptides. J Med Chem. 2003;46:156770.

18. Bisht GS, Rawat DS, Kumar A, Kumar R, Pasha S. Antimicrobial activity of rationally designed amino terminal modified peptides. Bioorg Med Chem Lett. 2007; 17:4343-6.

19. Makovitzki A, Baram J, Shai Y. Antimicrobial lipopolypeptides composed of palmitoyl Di- and tricationic peptides: in vitro and in vivo activities, self-assembly to nanostructures, and a plausible mode of action. Biochemistry. 2008;47:10630-6.

20. Laverty G, McLaughlin M, Shaw C, Gorman SP, Gilmore BF. Antimicrobial activity of short, synthetic cationic lipopeptides. Chem Biol Drug Des. 2010;75:5639.

21. Ceri H, Olson ME, Stremick C, Read RR, Morck D, Buret A. The Calgary Biofilm Device: new technology for rapid determination of antibiotic susceptibilities of bacterial biofilms. J Clin Microbiol. 1999;37:1771-6.

22. Kajiyama S, Tsurumoto T, Osaki M, Yanagihara K, Shindo H. Quantitative analysis of Staphylococcus epidermidis biofilm on the surface of biomaterial. J Orthop Sci. 2009; 14:769-75.

23. Mermel LA, Farr BM, Sherertz RJ, Raad II, O'Grady N, Harris JS, Craven DE, Infectious Diseases Society of America, American College of Critical Care Medicine, Society for Healthcare Epidemiology of America. Guidelines for the management of intravascular catheter-related infections. Clin Infect Dis. 2001;32:1249-72. 
24. Parsons C, McCoy CP, Gorman SP, Jones DS, Bell SE, Brady C, McGlinchey

SM. Anti-infective photodynamic biomaterials for the prevention of intraocular lensassociated infectious endophthalmitis. Biomaterials. 2009;30:597-602.

25. Lappe R, Cladera-Olivera F, Dominguez APM, Brandelli A. Kinetics and thermodynamics of thermal inactivation of the antimicrobial peptide cerein $8 \mathrm{~A}$. $\mathrm{J}$ Food Eng. 2009;91:223-7.

26. Andrews JM. Determination of minimum inhibitory concentrations. J Antimicrob Chemother. 2001;48 Suppl 1:5-16.

27. Jones DS, Andrews GP, Gorman SP. Characterization of crosslinking effects on the physicochemical and drug diffusional properties of cationic hydrogels designed as bioactive urological biomaterials. J Pharm Pharmacol. 2005;57:1251-9.

28. Guy RH, Hadgraft J. Theoretical comparison of release rates of drugs into sink and nonsink conditions. J Pharm Sci. 1981;70:1243-5.

29. Ritger PL, Peppas NA. A simple equation for description of solute release I. Fickian and non-fickian release from non-swellable devices in the form of slabs, spheres, cylinders or discs. J Controlled Release. 1987;5:23-36.

30. Peppas NA. Analysis of Fickian and non-Fickian drug release from polymers. Pharm Acta Helv. 1985;60:110-1.

31. Siepmann J, Peppas NA. Modeling of drug release from delivery systems based on hydroxypropyl methylcellulose (HPMC). Adv Drug Deliv Rev. 2001;48:139-57. 32. Wang X, Hu X, Daley A, Rabotyagova O, Cebe P, Kaplan DL. Nanolayer biomaterial coatings of silk fibroin for controlled release. J Control Release. 2007;121:190-9.

33. Costa P, Sousa Lobo JM. Modeling and comparison of dissolution profiles. Eur J Pharm Sci. 2001;13:123-33. 
34. Jones DS, Djokic J, Gorman SP. The resistance of polyvinylpyrrolidone-iodinepoly(-caprolactone) blends to adherence of Escherichia coli. Biomaterials. 2005;26:2013-20.

35. McCoy CP, Cowley JF, Gorman SP, Andrews GP, Jones DS. Reduction of Staphylococcus aureus and Pseudomonas aeruginosa colonisation on PVC through covalent surface attachment of fluorinated thiols. J Pharm Pharmacol. 2009;61:11639.

36. Jones DS, McGovern JG, Woolfson AD, Gorman SP. Role of physiological conditions in the oropharynx on the adherence of respiratory bacterial isolates to endotracheal tube poly(vinyl chloride). Biomaterials. 1997;18:503-10.

37. Jones DS, McGovern JG, Adair CG, Woolfson AD, Gorman SP. Conditioning film and environmental effects on the adherence of Candida spp. to silicone and poly(vinylchloride) biomaterials. J Mater Sci Mater Med. 2001;12:399-405. 38. Refojo MF, Yasuda H. Hydrogels from 2-hydroxyethyl methacrylate and propylene glycol monoacrylate. J App Polym Sci. 1965;9:2425-35.

39. Antonsen KP, Bohnert JL, Nabeshima Y, Sheu MS, Wu XS, Hoffman AS. Controlled release of proteins from 2-hydroxyethyl methacrylate copolymer gels. Biomater Artif Cells Immobilization Biotechnol. 1993;21:1-22.

40. Ratner BD, Miller IF. Transport through crosslinked poly(2-hydroxyethyl methacrylate) hydrogel membranes. J Biomed Mater Res. 1973;7:353-67.

41. Davis SS, Watson MA. The adsorption of cationic antimicrobial agents onto poly(Hema). Colloids and Surfaces. 1984;12:203-12.

42. Singh J, Agrawal K, Ray AR, Singhal JP, Singh H, Dada VK, Mehta MR. Polymeric hydrogels for soft contact lenses. J Biomed Mater Res. 1992;26:1253-7. 
43. Pillay V, Fassihi R. In vitro release modulation from crosslinked pellets for sitespecific drug delivery to the gastrointestinal tract. II. Physicochemical characterization of calcium-alginate, calcium-pectinate and calcium-alginate-pectinate pellets. J Control Release. 1999;59:243-56.

44. Kim H, Fassihi R. Application of binary polymer system in drug release rate modulation. 2. Influence of formulation variables and hydrodynamic conditions on release kinetics. J Pharm Sci. 1997;86:323-8.

45. Lin CC, Metters AT. Hydrogels in controlled release formulations: Network design and mathematical modelling. Adv Drug Deliv Rev. 2006;58:1379-408. 46. Khare AR, Peppas NA. Swelling/deswelling of anionic copolymer gels. Biomaterials. 1995;16:559-67.

47. Rinaki E, Valsami G, Macheras P. The power law can describe the 'entire' drug release curve from HPMC-based matrix tablets: a hypothesis. Int J Pharm. 2003;255:199-207.

48. Zuleger S, Lippold BC. Polymer particle erosion controlling drug release. I. Factors influencing drug release and characterization of the release mechanism. Int $\mathrm{J}$ Pharm. 2001;217:139-52.

49. Cramton SE, Gerke C, Schnell NF, Nichols WW, Gotz F. The intercellular adhesion (ica) locus is present in Staphylococcus aureus and is required for biofilm formation. Infect Immun. 1999;67:5427-33.

50. Curtin J, Cormican M, Fleming G, Keelehan J, Colleran E. Linezolid compared with eperezolid, vancomycin, and gentamicin in an in vitro model of antimicrobial lock therapy for Staphylococcus epidermidis central venous catheter-related biofilm infections. Antimicrob Agents Chemother. 2003;47:3145-8. 
51. Okajima Y, Kobayakawa S, Tsuji A, Tochikubo T. Biofilm formation by

Staphylococcus epidermidis on intraocular lens material. Invest Ophthalmol Vis Sci. 2006;47:2971-5.

52. Hancock RE, Fitz-James PC. Some differences in the action of penicillin, bacitracin, and vancomycin on Bacillus megaterium. J Bacteriol. 1964;87:1044-50.

53. Kodjikian L, Renaud FN, Roques C, Garweg JG, Pellon G, Freney J, Burillon C. In vitro influence of vancomycin on adhesion of a Staphylococcus epidermidis strain encoding intercellular adhesion locus ica to intraocular lenses. J Cataract Refract Surg. 2005;31:1050-8

54. McCann MT, Gilmore BF, Gorman SP. Staphylococcus epidermidis devicerelated infections: pathogenesis and clinical management. J Pharm Pharmacol. 2008;60:1551-71

55. Reddy KV, Yedery RD, Aranha C. Antimicrobial peptides: premises and promises. Int J Antimicrob Agents. 2004;24:536-47

\section{Legends for Figures}

FIGURE 1. The cumulative percentage drug release of $\mathrm{C}_{12}$-Orn-Orn-Trp-Trp- $\mathrm{NH}_{2}$ released $(\mu \mathrm{g})$ from a $0.5 \%, 1 \%$ and $5 \%$ matrix loaded poly(HEMA) hydrogel into $37^{\circ} \mathrm{C} 10 \mathrm{mLs}$ PBS, $\mathrm{pH} 7.4$, over a period of 2 weeks. Results are displayed as the mean of five replicates. Concentrations obtained via UV-visible spectroscopy from a fresh standard calibration curve (five replicates) of equation $y=0.0075 x\left(R^{2}=0.999\right.$, $280 \mathrm{~nm})$

FIGURE 2. The cumulative percentage drug release of $\mathrm{C}_{12}$-Orn-Orn-Trp-Trp- $\mathrm{NH}_{2}$ released $(\mu \mathrm{g})$ from a 20, 10 and $5 \mathrm{mg} / \mathrm{mL}$ immersion loaded poly(HEMA) hydrogel into $37^{\circ} \mathrm{C} 10 \mathrm{mLs}$ PBS, pH 7.4, over a period of 78 hours. Results are displayed as the 
mean of five replicates. Concentrations obtained via UV-visible spectroscopy from a fresh standard calibration curve (five replicates) of equation $\mathrm{y}=0.0075 \mathrm{x}\left(\mathrm{R}^{2}=0.999\right.$, $280 \mathrm{~nm})$

FIGURE 3. The mean percentage adherence (\%) of Staphylococcus epidermidis ATCC 35984 to $0.5 \%, 1 \%$ and 5\% vancomycin, maximin- 4 , H-Orn-Orn-Trp-Trp- $\mathrm{NH}_{2}$ and $\mathrm{C}_{12}$-Orn-Orn-Trp-Trp-NH 2 matrix loaded, 1\% EGDMA crosslinked, poly(HEMA) hydrogels relative to positive control (no drug) after 1 hour. Results are displayed as the mean of five samples

FIGURE 4. The mean percentage adherence (\%) of Staphylococcus epidermidis ATCC 35984 to $0.5 \%, 1 \%$ and 5\% vancomycin, maximin- 4 , H-Orn-Orn-Trp-Trp-NH $\mathrm{NH}_{2}$ and $\mathrm{C}_{12}$-Orn-Orn-Trp-Trp-NH 2 matrix loaded, 1\% EGDMA crosslinked, poly(HEMA) hydrogels relative to positive control (no drug) after 4 hours. Results are displayed as the mean of five samples

FIGURE 5. The mean percentage adherence (\%) of Staphylococcus epidermidis ATCC 35984 to $0.5 \%, 1 \%$ and 5\% vancomycin, maximin- 4 , H-Orn-Orn-Trp-Trp- $\mathrm{NH}_{2}$ and $\mathrm{C}_{12}$-Orn-Orn-Trp-Trp-NH 2 matrix loaded, 1\% EGDMA crosslinked, poly(HEMA) hydrogels relative to positive control (no drug) after 24 hours. Results are displayed as the mean of five samples

FIGURE 6. The mean percentage adherence (\%) of Staphylococcus epidermidis ATCC 35984 to 5, 10 and 20mg/mL vancomycin, maximin-4, H-Orn-Orn-Trp-Trp$\mathrm{NH}_{2}$ and $\mathrm{C}_{12}$-Orn-Orn-Trp-Trp- $\mathrm{NH}_{2}$ immersion loaded, 1\% EGDMA crosslinked, 
poly(HEMA) hydrogels relative to positive control (no drug) after 1 hour. Results are displayed as the mean of five samples

FIGURE 7. The mean percentage adherence (\%) of Staphylococcus epidermidis ATCC 35984 to 5, 10 and 20mg/mL vancomycin, maximin-4, H-Orn-Orn-Trp-Trp$\mathrm{NH}_{2}$ and $\mathrm{C}_{12}$-Orn-Orn-Trp-Trp- $\mathrm{NH}_{2}$ immersion loaded, 1\% EGDMA crosslinked, poly(HEMA) hydrogels relative to positive control (no drug) after 4 hours. Results are displayed as the mean of five samples

FIGURE 8. The mean percentage adherence (\%) of Staphylococcus epidermidis ATCC 35984 to 5, 10 and 20mg/mL vancomycin, maximin-4, H-Orn-Orn-Trp-Trp$\mathrm{NH}_{2}$ and $\mathrm{C}_{12}$-Orn-Orn-Trp-Trp- $\mathrm{NH}_{2}$ immersion loaded, 1\% EGDMA crosslinked, poly(HEMA) hydrogels relative to positive control (no drug) after 24 hours. Results are displayed as the mean of five samples

\section{Caption for all Figures}

Statistical significance (one way ANOVA and a Tukey-Kramer multiple comparisons test) of adherence to matrix loaded antimicrobial peptide hydrogels relative to the same \% loading and time point of standardised vancomycin control are indicated as follows:

$\mathrm{p}<0.001 * * *$

$\mathrm{p}<0.01 * *$

$\mathrm{p}<0.05 *$

ns: no significant difference

Matrix (5,1 and 0.5\%) and immersion (20, 10 and $5 \mathrm{mg} / \mathrm{mL})$ loaded vancomycin, maximin-4, H-Orn-Orn-Trp-Trp- $\mathrm{NH}_{2}$ and $\mathrm{C}_{12}$-Orn-Orn-Trp-Trp- $\mathrm{NH}_{2} 5,1$ and $0.5 \%$ display high significant differences $(\mathrm{p}<0.001)$ compared to positive controls at the same time points via a one way ANOVA and a Tukey-Kramer multiple comparisons test 